\title{
Appropriateness of Emergency Intubation and Its Clinical Outcome: A Prospective Audit of a Local Hospital in Malaysia
}

\author{
Li Cher $\mathrm{LOH}^{1 *}$, Eng Keat ONG ${ }^{1}$, Joshua Chin Ern $\mathrm{OOI}^{2}$, Sarah Sue Mei CHEW ${ }^{1}$, Kumaresh Raj LACHMANAN ${ }^{3}$, \\ Irfhan $\mathrm{ALI}^{3}$, Loke Meng $\mathrm{ONG}^{4}$ and Chew Har LIM ${ }^{5}$ \\ ${ }^{1}$ PMC Lung Research, Penang Medical College, Malaysia \\ ${ }^{2}$ RCSI Perdana University, Malaysia \\ ${ }^{3}$ Department of Respiratory Medicine, Penang Hospital, Malaysia \\ ${ }^{4}$ Deparatment of Medicine, Penang Hospital, Malaysia \\ ${ }^{5}$ Critical Care and Anaesthesiology Department, Penang Hospital, Malaysia \\ Submission: April 13, 2018; Published: April 26, 2018 \\ *Corresponding author: Li Cher LOH, Department of Medicine, Penang Medical College, 4 Jalan Sepoy Lines, Georgetown, 10450 Penang, \\ Malaysia, Tel: +604-228-7171; Fax: +604-228-4285; Email: richard_loh@pmc.edu.my
}

\begin{abstract}
Background: Intubation to provide ventilatory support in any patient is a serious decision. Inappropriate intubation is harmful and costly to healthcare.

Methods: A prospective audit to evaluate whether emergency intubation decisions were appropriate in medical patients of a state general hospital was conducted. All eligible cases were consecutively recruited and followed up for 3 months. Surgical and cardiac cases were excluded. The specialist physician and anaesthetist in charge judged whether the emergency intubation was appropriate based on disease reversibility, premorbid status and ethical consideration. The intubation was considered inappropriate if either one judged so.

Results: 105 cases were audited [70 males; mean age (range) 59 (28 to 86) yrs]. 52.3\% had sepsis and 48.5\% had pneumonia as cause for intubation. $16(17.9 \%)$ patients were inappropriately intubated. None of the inappropriately intubated survived in 3 months while $34(38.8 \%)$ of appropriately ventilated cases did. Multivariate logistic regression showed that inappropriate intubation was associated with on-call working shift and non-ICU care while mortality was associated with age, total SOFA score and non-ICU care. Inappropriate ventilation was associated with reduced probability of survival (log-rank test, $\mathrm{p}<0.001$ ) but not so when adjusted with age, SOFA score and non-ICU care (Adjusted HR 1.33; $0.68-2.61 ; \mathrm{p}=0.39$ ).
\end{abstract}

Conclusion: A significant proportion of emergency intubations was inappropriate and had poor outcomes. Our audit results identify several issues for intervention and reiterate that the decision to intubate patients must be carefully weighed.

Keywords: Emergency intubation; Cardio-respiratory arrest; Decision; Appropriateness; Malaysia

\section{Introduction}

Intubation to provide assisted ventilation is a serious decision. It is an invasive procedure and the ensuing mechanical ventilation is intensive and costly from the perspectives of medical and nursing care [1]. Intubated patients are normally managed in intensive care unit (ICU). In some hospitals in Malaysia, the shortage of ICU beds has led to the situation where the emergency intubated patients have to be temporarily managed in general medical wards. They are however continued to be cared for in a high-dependency manner by both the physicians and anaesthetists. One reason noted for the constantly full occupancy of ICU beds with patients consequently managed outside ICU is that too many patients are being considered for intubation. This scenario is apparently common in many public hospitals in Malaysia but the exact statistics are not available. There are also anecdotal reports of such occurrence in hospitals among resource-poor areas of other low-to-medium income countries. The reason for the lack of such statistics may be due to the sensitive nature of such information. The low threshold for emergency intubation in our hospital needs to be investigated. In a prospective clinical audit, we examined all consecutive medical cases that had emergency intubation in our hospital were appropriate. We also evaluated factors associated on this appropriateness on emergency intubation and the clinical outcomes of mortality and length of hospital stay. 


\section{Patients and Methods}

\section{Study design}

All consecutive medical patients who had emergency intubation in a large 1200-bed urban-based state general hospital (Penang Hospital, Penang) was audited within two working days of intubation. The audit cases were recruited from June to August 2013 (three months) and followed up until three months from the date of intubation. For the purpose of this audit, we excluded surgical and cardiac cases since the causes of intubation are usually obvious and warranted. Only intubation carried out as a medical emergency was considered for the audit. During these emergencies, the decision to intubate was made by the physician team (who might be consultant, specialist or medical officer) who looked after these patients during working hours or the medical officer on-call during offworking hours. Anaesthetist colleagues (either during working or off-working hours) were usually asked to assist to perform intubation. This audit was jointly conducted by Department of Medicine, Department of Respiratory Medicine, Critical Care and Anaesthesiology Department, Penang Hospital and Department of Medicine, Penang Medical College, Penang.

\section{Data collection and judgment on "appropriateness" of intubation}

Data was collected using standardized questionnaire that included all relevant demographic, clinical and healthcare process details (e.g. normal or on-call hours). The "appropriateness" of intubation was based on the judgement by the in-charge specialist/consultant physician and the in-charge specialist/ Results consultant anaesthetist obtained from face-to-face interview by the investigators (EKO, JCEO, SSMC) within two working days from the time of intubation. The in-charged specialist/ consultant might or might not be the person who decided on the emergency intubation. The judgment was based on the three criteria of disease reversibility, premorbid status and ethical consideration. The two judges were interviewed independent from each other. The case was judged inappropriate if either one of the two senior doctors considered so. All cases were followed up for three months until death or discharge.

\section{Audit standard}

We arbitrarily set the audit standard of acceptable rate for "inappropriate" intubation at $10 \%$ given the difficulty and the sensitive nature of such decision for the deciding doctors.

\section{Statistical analysis}

Categorical and continuous data are analyzed by Chi Square and t-tests respectively. Variables with p value $<0.05$ are included into univariate and multivariate logistic regression analysis to calculate crude and adjusted odd ratios for associations with 'inappropriate' intubation and mortality. Hosmer-Lemeshow test is used to ensure the variables fit the model. Kaplan-Meier curve is used to show association between length of hospital stay and 'inappropriate' intubation, and their associations are analyzed using log-rank test and Cox-proportional hazards model. Test of proportional hazards assumption is used to ensure the variables fit the model. A p value $<0.05$ is considered statistically significant.

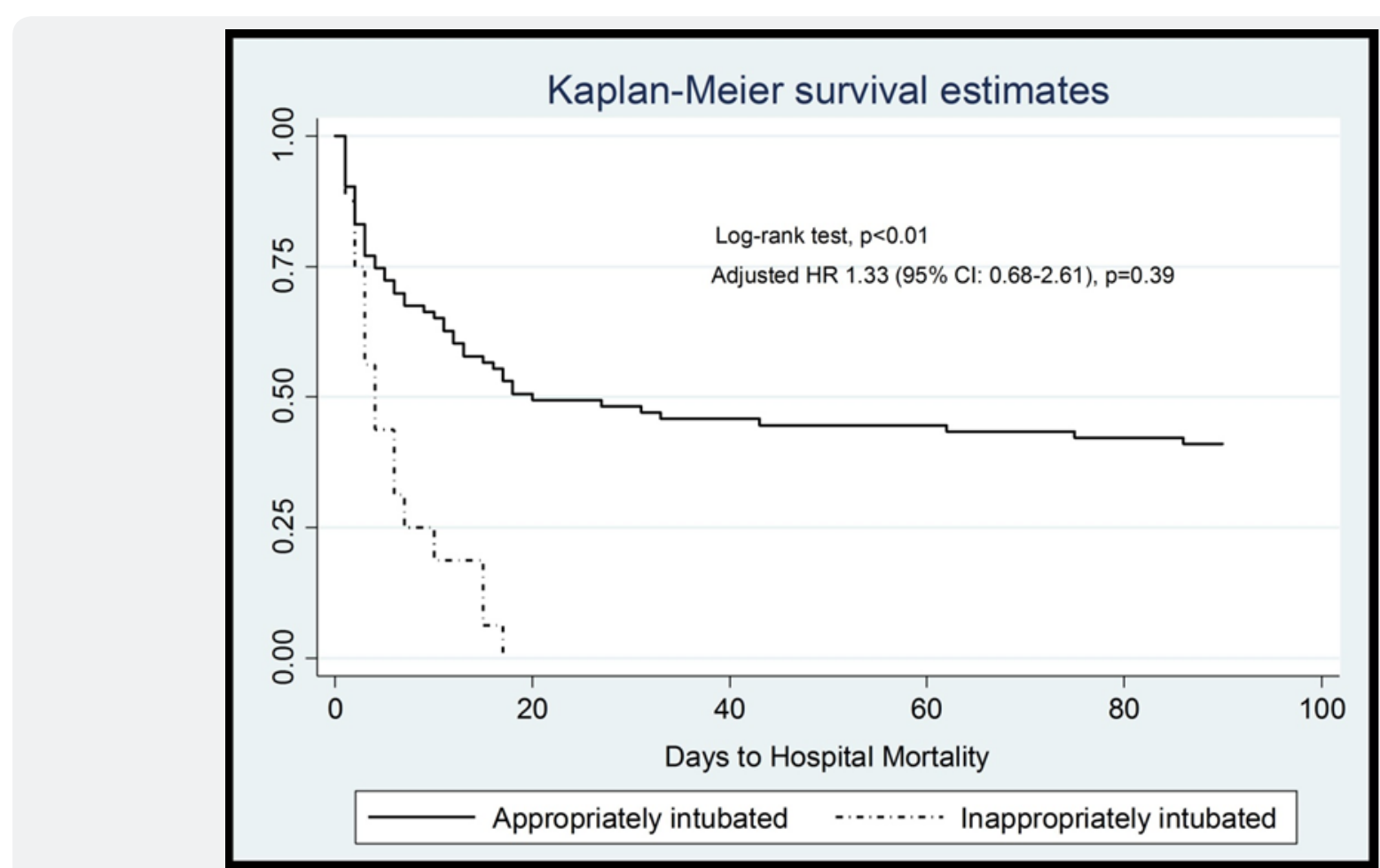

Figure 1: Kaplan-Meier survival estimates according to appropriateness of intubation. 
A total of 105 patients [mean age 59 yrs (range 28 to 86); $66 \%$ male] were audited and all follow-ups were complete. Over half were Chinese and near a quarter were Malay. 52.3\% had sepsis and $48.5 \%$ had pneumonia as cause for intubation. Their premorbid medical conditions, whether respiratory or non-respiratory, were not significantly different between those appropriately and inappropriately intubated (data not shown). Sixteen $(17.9 \%)$ patients were inappropriately intubated. The highest proportion of the inappropriately intubated cases $(37 \%)$ occurred in the neurology/endocrine ward (this is a shared ward between the two specialties) while the highest proportion of the appropriately intubated cases (33\%) occurred in Accident \& Emergency (A \& E) Department. None of the inappropriately intubated survived in 3 months while 34 (38.8\%) of appropriately ventilated cases did (Figure 1).

\section{Association with "inappropriate" group}

Table 1: Demographic and total SOFA score of patients according to appropriateness of intubation.

\begin{tabular}{|c|c|c|c|c|}
\hline & Inappropriate & Appropriate & Total & $\mathbf{p}^{*}$ \\
\hline & $(n=16)$ & $(n=89)$ & $(n=105)$ & \\
\hline Male & $9(56)$ & $61(68)$ & $70(66)$ & 0.337 \\
\hline $\begin{array}{l}\text { Age, mean } \\
\text { yrs (SD) }\end{array}$ & $69(11.5)$ & 57 (15.9) & $59(15.8)$ & 0.004 \\
\hline \multicolumn{5}{|l|}{$\begin{array}{c}\text { Age Group, } \\
\text { yrs }\end{array}$} \\
\hline$\leq 40$ & $1(6)$ & $15(16)$ & $16(15)$ & - \\
\hline 41 to 50 & $0(0)$ & $9(10)$ & $9(8)$ & - \\
\hline 51 to 60 & $2(12)$ & $24(26)$ & $26(24)$ & - \\
\hline 61 to 70 & $5(31)$ & $14(15)$ & $19(18)$ & - \\
\hline$\geq 71$ & $8(50)$ & $27(30)$ & $5(33)$ & 0.129 \\
\hline \multicolumn{5}{|l|}{ Ethnicity } \\
\hline Malay & $1(6)$ & $25(28)$ & $26(24)$ & - \\
\hline Chinese & $12(75)$ & $6(51)$ & $58(55)$ & - \\
\hline Indian & $3(18)$ & $15(16)$ & 18 (17) & - \\
\hline Others & $0(0)$ & $3(3)$ & $3(2)$ & 0.211 \\
\hline $\begin{array}{l}\text { SOFA, mean } \\
\text { (SD) }\end{array}$ & $9.1(3.05)$ & $8.9(3.95)$ & $8.9(3.95)$ & 0.819 \\
\hline
\end{tabular}

Figures shown are number (percentage) unless otherwise specified

*Comparing 'Inappropriate' vs. 'appropriate' groups;

SOFA: Sepsis-related Organ Failure Assessment Score
Table 2: Healthcare process according to appropriateness of intubation.

\begin{tabular}{|c|c|c|c|c|}
\hline & Inappropriate & Appropriate & Total & $\mathbf{p}^{*}$ \\
\hline & $(n=16)$ & $(n=89)$ & $(n=105)$ & \\
\hline \multicolumn{5}{|l|}{$\begin{array}{l}\text { Location of } \\
\text { Intubation }\end{array}$} \\
\hline ICU & $0(0)$ & $7(7)$ & $7(6)$ & - \\
\hline $\begin{array}{c}\text { General } \\
\text { medicine** }\end{array}$ & $1(6)$ & $10(11)$ & $11(10)$ & - \\
\hline $\begin{array}{l}\text { Endocrine/ } \\
\text { Neurology\# }\end{array}$ & $6(37)$ & $15(16)$ & $21(20)$ & - \\
\hline Nephrology & $1(6)$ & $7(7)$ & $8(7)$ & - \\
\hline Cardiology & $0(0)$ & $1(1)$ & $1(1)$ & - \\
\hline Respiratory & $3(18)$ & $16(17)$ & 19(17) & - \\
\hline$A \& E$ & $3(18)$ & $30(33)$ & $33(31)$ & - \\
\hline Others ${ }^{* * *}$ & $2(12)$ & $3(3)$ & $5(4)$ & 0.428 \\
\hline \multicolumn{5}{|l|}{ Doctor's Shift } \\
\hline Normal hours & $1(6)$ & $31(34)$ & $32(30)$ & - \\
\hline On call hours & $15(93)$ & $58(65)$ & $73(69)$ & 0.022 \\
\hline \multicolumn{5}{|l|}{ Rank of doctor } \\
\hline Medical officer & $11(68)$ & $76(85)$ & $87(82)$ & - \\
\hline $\begin{array}{l}\text { Specialist/ } \\
\text { Consultant }\end{array}$ & $5(31)$ & $13(14)$ & $18(17)$ & 0.104 \\
\hline \multicolumn{5}{|l|}{$\begin{array}{c}\text { Deciding } \\
\text { Department }\end{array}$} \\
\hline$A \& E$ & $3(18)$ & $28(31)$ & $31(29)$ & - \\
\hline Medical & $11(68)$ & $44(49)$ & $55(52)$ & - \\
\hline $\begin{array}{l}\text { Anesthes } \\
\text { iology }\end{array}$ & $1(6)$ & $16(17)$ & $17(16)$ & - \\
\hline Surgery & $1(6)$ & $1(1)$ & $2(2)$ & 0.193 \\
\hline \multicolumn{5}{|l|}{$\begin{array}{c}\text { Transferred } \\
\text { into ICU }\end{array}$} \\
\hline Yes & $36(40)$ & $1(6)$ & $37(35)$ & - \\
\hline No & $53(59)$ & $15(93)$ & $68(64)$ & 0.008 \\
\hline \multicolumn{5}{|l|}{$\begin{array}{l}\text { Care after } \\
\text { Intubation }\end{array}$} \\
\hline ICU & $1(6)$ & $57(64)$ & $58(55)$ & - \\
\hline Non-ICU & $15(93)$ & $32(35)$ & $47(44)$ & $<0.001$ \\
\hline \multicolumn{5}{|l|}{$\begin{array}{c}\text { Intubation } \\
\text { Difficulty }\end{array}$} \\
\hline Easy & $12(75)$ & $77(86)$ & $89(84)$ & - \\
\hline Difficult & $4(25)$ & $12(13)$ & $16(15)$ & 0.532 \\
\hline
\end{tabular}

*Comparing 'Inappropriate' vs. 'appropriate' groups;

**General Medicine (including infectious disease, rheumatology, gastroenterology)

***Included surgical, hematological wards

\# This is a shared ward between the two specialties

A \& E: Accident \& Emergency Ward; ICU: Intensive Care Unit 
International Journal of Pulmonary \& Respiratory Sciences

Table 3: Logistic regression on factors associated with "inappropriate" intubation.

\begin{tabular}{|c|c|c|c|c|}
\hline & \multicolumn{2}{|c|}{ Crude effects } & \multicolumn{2}{c|}{ Adjusted Effects* } \\
\hline & Odd Ratios & $\mathbf{9 5 \%}$ CI & Odd Ratios & $\mathbf{9 5 \%}$ CI \\
\hline Age group & 1 & $1.01-1.12$ & 0.9 & $0.93-1.05$ \\
\hline On-call shift & 8 & $1.01-63.57$ & 14.9 & $1.65-134.68$ \\
\hline $\begin{array}{c}\text { Non-ICU } \\
\text { care }\end{array}$ & 26.7 & $3.37-211.74$ & 36.1 & $3.82-342.23$ \\
\hline
\end{tabular}

*Variables included for adjustment are age group, on-call shift and non-ICU care.

"Inappropriate" group was significantly older than the "appropriate" group (Table 1). Proportionately more "inappropriate" group occurred during on-call hours compared to normal working hours and were managed in non-ICU wards compared to ICU (Table 2). In logistic regression analysis, increasing age was associated with the likelihood of being in 'inappropriate' group but not so after adjusting for on-call hours and non-ICU care. On-call hours and non-ICU care were 8 and 26 times more likely to be associated with 'inappropriate' group respectively. These likelihoods increased further to 14 and 36 times after adjusting for age and each other. The 95\% confidence levels for both however were very wide, suggesting a wide variability between cases (Table 3 ).

\section{Association with hospital mortality}

Table 4: Demographic and total SOFA score of patients accordig to mortality

\begin{tabular}{|c|c|c|c|c|}
\hline & Survival & Dead & Total & $\mathbf{p}^{*}$ \\
\hline Male & 25(75) & 45(63) & $70(66)$ & 0.302 \\
\hline $\begin{array}{c}\text { Age, mean } \\
\text { yrs(SD) }\end{array}$ & $50(16.0)$ & $63(13.9)$ & $59(15.8)$ & $<0.001$ \\
\hline $\begin{array}{c}\text { Age } \\
\text { group, } \\
\text { yrs }\end{array}$ & & & & \\
\hline$\leq 40$ & $10(29)$ & $6(8)$ & $16(15)$ & - \\
\hline $\begin{array}{c}\text { 41 to 50 } \\
\text { 51 to 60 }\end{array}$ & $10(11)$ & $5(7)$ & $9(8)$ & - \\
\hline 61 to 70 & $6(17)$ & $16(22)$ & $26(24)$ & - \\
\hline$\geq 71$ & $4(11)$ & $31(43)$ & $35(33)$ & 0.005 \\
\hline Ethnicity & & $19(18)$ & - \\
\hline Malay & $10(29)$ & $16(22)$ & $26(24)$ & - \\
\hline Chinese & $16(47)$ & $42(59)$ & $58(55)$ & - \\
\hline $\begin{array}{c}\text { Indian } \\
\text { Others }\end{array}$ & $6(17)$ & $12(16)$ & $18(17)$ & - \\
\hline $\begin{array}{c}\text { SOFA } \\
\text { score, } \\
\text { mean(SD) }\end{array}$ & $7.2(4.06)$ & $9.9(3.58)$ & $8.9(3.95)$ & 0.001 \\
\hline
\end{tabular}

Figures shown are number (percentage) unless otherwise specified *comparing 'survival' vs. 'dead' groups;

SOFA: Sepsis-related Organ Failure Assessment Score
Table 5: Healthcare process according to mortality.

\begin{tabular}{|c|c|c|c|c|}
\hline & Survival & Dead & Total & *p \\
\hline & $(n=34)$ & $(n=71)$ & $(n=105)$ & \\
\hline \multicolumn{5}{|l|}{$\begin{array}{l}\text { Location of } \\
\text { Intubation }\end{array}$} \\
\hline ICU & $5(14)$ & $2(2)$ & $7(6)$ & - \\
\hline $\begin{array}{c}\text { General } \\
\text { medicine** }\end{array}$ & $2(5)$ & $9(12)$ & 11(10) & - \\
\hline $\begin{array}{l}\text { Endocrine \& } \\
\text { Neurology }\end{array}$ & $3(8)$ & $18(25)$ & $21(20)$ & - \\
\hline Nephrology & $2(5)$ & $6(8)$ & $8(7)$ & - \\
\hline Cardiology & $1(2)$ & $0(0)$ & $1(0)$ & - \\
\hline Respiratory & $5(13)$ & $14(19)$ & $19(17)$ & - \\
\hline$A \& E$ & $14(41)$ & $19(26)$ & $33(31)$ & - \\
\hline Others ${ }^{* * *}$ & $2(5)$ & $3(4)$ & $5(4)$ & 0.081 \\
\hline \multicolumn{5}{|l|}{ Doctor's Shift } \\
\hline Normal hours & $9(26)$ & $23(32)$ & $32(30)$ & - \\
\hline On call hours & $25(73)$ & $48(67)$ & $73(69)$ & 0.537 \\
\hline \multicolumn{5}{|l|}{ Rank of doctor } \\
\hline Medical officer & $29(85)$ & $58(81)$ & $87(82)$ & - \\
\hline $\begin{array}{l}\text { Specialist/ } \\
\text { Consultant }\end{array}$ & $5(14)$ & $13(18)$ & $18(17)$ & 0.647 \\
\hline \multicolumn{5}{|l|}{$\begin{array}{c}\text { Deciding } \\
\text { Department }\end{array}$} \\
\hline$A \& E$ & $14(41)$ & $17(23)$ & $31(29)$ & - \\
\hline Medical & $10(29)$ & $45(63)$ & $55(52)$ & - \\
\hline Anesthesiology & $10(29)$ & $7(9)$ & $17(16)$ & - \\
\hline Surgery & $0(0)$ & $2(2)$ & $2(1)$ & 0.003 \\
\hline \multicolumn{5}{|l|}{$\begin{array}{l}\text { Care after } \\
\text { Intubation }\end{array}$} \\
\hline ICU & $31(91)$ & $27(38)$ & $58(55)$ & - \\
\hline Non-ICU & $3(8)$ & $44(61)$ & $47(44)$ & $<0.001$ \\
\hline \multicolumn{5}{|l|}{$\begin{array}{l}\text { Difficulty of } \\
\text { Intubation }\end{array}$} \\
\hline Easy & $32(94)$ & $57(80)$ & $89(84)$ & - \\
\hline Difficult & $2(5)$ & $14(19)$ & $16(15)$ & 0.065 \\
\hline
\end{tabular}

Figures shown are number (percentage) unless otherwise specified

*comparing 'survival' vs. 'dead' groups;

**General Medicine (including infectious disease, rheumatology, gastroenterology)

***Included surgical, hematological wards

A \& E: Accident \& Emergency Ward; ICU: Intensive Care Unit 
Table 6: Logistic regression on factors associated with mortality.

\begin{tabular}{|c|c|c|c|c|}
\hline & \multicolumn{2}{|c|}{ Crude Effects } & \multicolumn{2}{c|}{ Adjusted Effects* } \\
\hline & Odd Ratios & $\mathbf{9 5 \%}$ CI & Odd Ratios & $\mathbf{9 5 \% ~ C I ~}$ \\
\hline Age Group & 1.7 & $1.29-2.45$ & 1.6 & $1.05-2.49$ \\
\hline SOFA Score & 1.2 & $1.07-1.39$ & 1.3 & $1.12-1.59$ \\
\hline $\begin{array}{c}\text { Non-ICU } \\
\text { Care }\end{array}$ & 16.8 & $4.69-60.46$ & 16.7 & $3.09-72.21$ \\
\hline
\end{tabular}

SOFA: Sepsis-related Organ Failure Assessment

*Variables included for adjustment are age group, total SOFA scoreand non-ICU care. Deciding department and "inappropriate" intubation group are not included.

Mortality group was significantly older than those who lived. Mean total score for Sepsis-related Organ Failure Assessment (SOFA) was significantly higher in mortality group compared to survival group (Table 4). The difference in departments (who decided to intubate) and whether it was ICU or non-ICU care were statistically significant between the two groups (Table 5 \& 6). In logistic regression analysis, increasing age, raising total SOFA score and non-ICU care were significantly associated with likelihood of mortality, but not deciding department. These associations remained independently association with mortality after adjusting for age and one another. The odd ratios changed little with or without adjustment, suggesting that they were highly independent from one another. The odd ratio for nonICU care is much higher than age or total SOFA score. Kaplan Meier survival estimates showed that "inappropriate" group was significantly associated with reduced days to mortality (log rank $\mathrm{p}<0.001$ ). This association is not significant when adjusted with age, total SOFA score and non-ICU care [adjusted Hazard Ratio ( $95 \% \mathrm{CI}$ ): 1.33 (0.68 to 2.61); $\mathrm{p}=0.39$ ].

\section{Discussion}

Our audit showed that there was a higher than $10 \%$ rate (our arbitrary audit cut-off point) of inappropriately intubated emergency cases in our hospital. Significantly more cases occurred during on-call hours and were managed in non-ICU setting compared to those appropriately intubated. Mortality within three months were associated with older age, those who were critically more ill as reflected by total SOFA score and with non-ICU care. Inappropriate intubation increased the probability of death by survival estimates. The increase however was not significant after adjusting for total SOFA score, age and non-ICU care.

To our knowledge, this is the first ever published audit on this issue. The judgment of whether intubation was appropriate was considered strict and was generally independent from the doctor who decided on the emergency intubation. While the general principles on consideration for intubation are well established, doctors including consultants can still disagree on individual cases [2].ᄀ This indicates that the decision to intubate or not is never an overtly straightforward one. The highest proportion of inappropriately intubated cases occurred in endocrine/neurology ward. Further data analysis revealed that they were mostly neurological cases rather than endocrine cases. This may suggest that neurological cases encountered a more difficult decision on the issue of emergency intubation in general or possibly reluctance to commit on such issue. This audit finding had been discussed and conveyed to the relevant physicians in charge.

The finding that more inappropriately intubated cases had occurred during on-call hours had raised the important issue of whether on-call doctors had a lower threshold of intubating patients rightly or wrongly. It is obviously a more difficult decision to call off intubation during a respiratory arrest of a patient who is normally not cared for by the on-call doctors. The medically correct decision is to proceed to intubate if in doubt since saving life is the obvious priority. The decision is a sensitive one with the patient's family and has medico-legal consequences [3].

Our audit finding also raises the issue of whether the managing doctors had made proper documentation of "notfor-resuscitation" (DNR) order and whether such message had been properly "handover" to on-call doctors if such decision was made. The importance and practice of proper clinical handover between clinicians and medical documentation is not new and has been emphasized in many clinical guidelines over the years $[4,5]$. Despite this, many sites still show significant lapses of such practice till today [6]. The reality is that DNR orders are difficult and complex decisions [7], and that many doctors are uncomfortable discussing about DNR decisions with patients and families [8]. It is highly likely that our doctors faced the same struggle.

Non-ICU care of intubated patients was significantly associated with both "inappropriate" intubation and hospital mortality. Importantly, the confidence levels of the adjusted odd ratio for both these variables are very wide, suggesting that the variability of probabilities is huge. Our audit showed that significantly more patients who were appropriately ventilated were subsequently transferred into ICU from the initial site of intubation (either A \& E or general ward) than those inappropriately ventilated ( $40 \%$ vs. $6 \%$ ). This indicated that there was an active selection process of cases to be treated in ICU. This active selection was very likely to have contributed to our audit findings of increased mortality and "inappropriate" intubation among the non-ICU cases. The interpretation of our findings must take this into account. Since "inappropriate" intubation cases were judged as poor premorbid status and disease reversibility, these non-ICU cases were likely those with poorer clinical prognosis and high mortality risk.

The practice of managing intubated patients in non-ICU setting is a pragmatic but practical solution to the frequent crisis of ICU bed shortage in Malaysia. Apparently, such practice also is also known to occur elsewhere from personal communications. 
Although non-invasive ventilation can be executed outside ICU to some success [9], invasive ventilation outside ICU is generally not accepted as the standard care of practice because of its high level of nursing care. The non-ICU care is intended as a temporary measure while waiting for ICU bed to be available. In our hospital, they are conducted in a high-dependency manner near to nurses' station and cared for by ward physicians as well as anaesthetists from ICU. The incidence of such cases can be minimized if we are more effective in selection of appropriate cases for intubation.

In short, our audit has identified several potential areas to intervene in order to reduce the incidence of inappropriate intubation. To date, we had several discussions between departments on the audit findings and had implemented some action plans. However doctor education, departmental cooperation and the vigilance of intubation practice must be on-going to ensure that inappropriate intubation is kept to a minimum and that ICU beds are freed up to service our healthcare system. Plans for re-auditing this are being discussed.

\section{Acknowledgment}

The authors wish to thank the Penang Hospital Director and Director-General, Ministry of Health Malaysia for the support of this audit.

\section{References}

1. Dasta JF, McLaughlin TP, Mody SH, Piech CT (2005) Daily cost of an intensive care unit day: The contribution of mechanical ventilation. Crit Care Med 33(6): 1266-1271

This work is licensed under Creative Commons Attribution 4.0 License

DOI: 10.19080/IJOPRS.2018.03.555605
2. Wildman MJ, O Dea J, Kostopoulou O, Tindall M (2003) Variation in intubation decisions for patients with chronic obstructive pulmonary disease in one critical care network. Q J Med 96(8): 583-591.

3. Peters M, Kern BR, Buschmann C (2015) Medicolegal aspects in emergency medical care: Analysis of the frequency of advance health care directives and the influence on decision making in emergency medicine. Med Klin Intersivemed Notfmed.

4. National Patient Safety Agency (2004) Safe handover: safe patients. Guidance on clinical handover for clinicians and managers. Guidance on clinical handover for clinicians and managers London: British Medical Association/National Patient Safety Agency/NHS Modernisation Agency.

5. Australian Commission on Safety and Quality in Healthcare (2011) National Safety and Quality Health Service Standards. ACSQHS, Sydney, Australia.

6. Pascoe H, Gill SD, Hughes A, McCall White M (2014) Clinical handover An audit from Australia. Australas Med J 7(9): 363-371.

7. Mockford C, Fritz Z, George R, Court R, Grove A, et al. (2015) Do not attempt cardiopulmonary resuscitation (DNACPR) orders: a systemic review of the barriers and facilitators of decision-making and implementation. Resuscitation 88: 99-113.

8. Cohn S, Fritz ZB, Frankau JM, Laroche CM, Fuld JP (2013) Do Not Attempt Cardiopulmonary Resuscitation orders in acute medical settings: a qualitative study. QJM 106(2): 165-177.

9. Cabrini L, Antonelli M, Savoia G, Landriscina M (2011) Non-invasive ventilation outside of Intensive Care Unit: an Italian survey. Minerva Anestesiol 77(3): 313-322.

Your next submission with Juniper Publishers will reach you the below assets

- Quality Editorial service

- Swift Peer Review

- Reprints availability

- E-prints Service

- Manuscript Podcast for convenient understanding

- Global attainment for your research

- Manuscript accessibility in different formats

( Pdf, E-pub, Full Text, Audio)

- Unceasing customer service

Track the below URL for one-step submission https://juniperpublishers.com/online-submission.php 